\title{
Clinical usefulness of the metabolic syndrome for the risk of coronary heart disease does not exceed the sum of its individual components in older men and women. The Three-City (3C) Study
}

\author{
Antoine Rachas, ${ }^{1}$ Christelle Raffaitin, ${ }^{2}$ Pascale Barberger-Gateau, ${ }^{2}$ Catherine Helmer, ${ }^{2}$ \\ Karen Ritchie, ${ }^{3}$ Christophe Tzourio, ${ }^{4}$ Philippe Amouyel, ${ }^{5}$ Pierre Ducimetière, ${ }^{6}$ \\ Jean-Philippe Empana ${ }^{1}$
}

\begin{abstract}
- Additional figures and tables are published online only. To view these files please visit the journal online (http://heart.bmj. com/content/98/8.toc).

${ }^{1}$ Paris Cardiovascular Research Centre, University Paris Descartes, Sorbonne Paris Cité, UMR-S970, Paris, France ${ }^{2}$ INSERM U897, Université Victor Segalen Bordeaux 2, Bordeaux, France ${ }^{3}$ INSERM U1061, Montpellier 1 University, Montpellier, France ${ }^{4}$ INSERM U708, Hôpital de la Pitié-Salpêtrière, Paris, France ${ }^{5}$ INSERM U744, Institut Pasteur de Lille, Lille, France

${ }^{6}$ IFR69, Paris-Sud University, Villejuif, France
\end{abstract}

Correspondence to Dr Jean-Philippe Empana, INSERM U970, Paris

Cardiovascular Research Center (PARCC), 56 rue Leblanc, Paris 75015, France; jean-philippe. empana@inserm.fr

Accepted 31 January 2012

\section{ABSTRACT}

Objectives To investigate the respective associations and clinical usefulness of the metabolic syndrome (MetS) and its individual components to predict the risk of first coronary heart disease (CHD) events in elderly. Design The Three-City is a French prospective multisite community-based cohort.

Setting Three large French cities: Bordeaux, Dijon and Montpellier.

Participants 7612 subjects aged 65 and over who were free of $\mathrm{CHD}$ at baseline.

Main outcome measures The MetS was defined by the 2005 National Cholesterol Education Program Adult Treatment Panel III criteria.

Results During a median follow-up of 5.2 years, 275 first CHD events were adjudicated. The MetS was associated with increased risks of total (adjusted HR: 1.78; $95 \%$ Cl 1.39 to 2.28), fatal (HR: $2.40 ; 95 \% \mathrm{Cl} 1.41$ to 4.09 ) and non-fatal (HR: $1.64 ; 95 \% \mathrm{Cl} 1.24$ to 2.17$)$ $\mathrm{CHD}$ events. The association with total $\mathrm{CHD}$ was significant in women (HR: 2.56; 95\% Cl 1.75 to 3.75) but not in men (HR: $1.39 ; 95 \% \mathrm{Cl} 0.99$ to 1.94 ; p for interaction $=0.012$ ). When in the same multivariable model, hyperglycemia and abdominal adiposity in women, hyperglycemia, lower HDL cholesterol and abdominal adiposity (inverse association) in men were the components significantly associated with $\mathrm{CHD}$. The components of the MetS but not the MetS itself improved risk prediction beyond traditional risk factors (NRI $=9.35 \%, p<0 ; 001$ ).

Conclusion The MetS is a risk marker for $\mathrm{CHD}$ in community-dwelling elderly subjects but may not be useful for CHD risk prediction purposes compared to its individual components.

\section{INTRODUCTION}

The metabolic syndrome (MetS) has been widely associated with incident type II diabetes, cardiovascular disease (CVD) and total mortality risks primarily in the middle-aged. ${ }^{1-4}$ The incidence rate of CHD and the prevalence of the MetS both increase with age, suggesting that assessing the association between the MetS and CHD risk in elderly may have public health implications. In a recent cross-sectional analysis of the Three City
Study involving French community-based older adults, participants with the MetS at baseline had higher degree of subclinical atherosclerosis as measured by the presence of carotid plaques and intima-media thickness. ${ }^{5}$ This suggests that the MetS may be a risk marker for CHD in older adults. So far however, this issue has been addressed by only few studies. ${ }^{6-9}$ Except the Cardiovascular Health Study, these studies covered a restricted age range (60-79 years or 70-79 years) and in one study, participants were all women. ${ }^{6-9}$ Most studies used the 2001 NCEP ATP III criteria although significant changes and new definitions occurred since $2005 .^{10-13}$ The impact of these changes on the association between the MetS and subsequent $\mathrm{CHD}$ has yet not been systematically evaluated in the elderly population. Moreover, there is still controversy as to whether the MetS adds predictive information for $\mathrm{CHD}$ risk beyond its individual components. This is a major question as it raises the clinical usefulness of the MetS.

Therefore, our aims were first to quantify the associations between the MetS and its individual components with the risk of CHD and second to evaluate the added value of the MetS for CHD risk prediction beyond its individual components. These two issues were addressed in older men and women who were participants of the Three City Study. ${ }^{14}$

\section{METHODS}

\section{Study population}

The Three-City Study is a French multicentre prospective cohort investigating the determinants of $\mathrm{CHD}$, stroke and dementia in communitydwelling elderly. Details of the protocol have been previously described. ${ }^{14}$ Briefly, communitydwellers aged 65 years and over were selected from the electoral rolls of three large cities and then invited to participate in the study. Overall, 9294 subjects (3649 men and 5645 women) agreed to participate in the study including 2104 from Bordeaux (South-West), 4931 from Dijon (NorthEast) and 2259 from Montpellier (South). The study protocol had been approved by the Ethical Committee of the University Hospital of KremlinBicêtre. Each participant had signed an informed consent. 


\section{Baseline data collection and examination}

Trained interviewers conducted face-to-face interviews, using a standardised questionnaire. A wide range of information was collected including demographic characteristics, educational level, occupation, daily life habits such as smoking and alcohol consumption and functional status. Past history of $\mathrm{CHD}$ included history of angina pectoris, myocardial infarction or revascularisation procedure (percutaneous transluminal angioplasty or coronary bypass graft surgery). Information on all medications they had regularly used in the past month was also recorded. Brachial blood pressure was measured twice after at least $5 \mathrm{~min}$ of rest in a seated position, with an appropriately sized cuff placed on the right arm, using a validated digital electronic tensiometer (OMRON M4, OMRON Corp., Kyoto, Japan). Height and weight were measured in a subject in a light dressing. Blood was collected following overnight fasting and centralised standard measurements of lipids and glucose levels were performed. Diabetes was defined as a fasting blood glucose level $\geq 7 \mathrm{mmol} / \mathrm{l}$ and/or drug treatment for diabetes. LDL cholesterol level was calculated using Friedewald equation for triglycerides values $\leq 4.5 \mathrm{~g} / \mathrm{l}$.

\section{MetS definitions}

The main analysis was performed using the 2005 revised National Cholesterol Education Program Adult Treatment Panel III (NCEP ATP III) definition (11), requiring the presence of at least three of the following criteria: abdominal obesity (waist circumference $\geq 102 \mathrm{~cm}$ in men and $\geq 88 \mathrm{~cm}$ in women); triglycerides level $\geq 150 \mathrm{mg} / \mathrm{dl}(1.7 \mathrm{mmol} / \mathrm{l})$ or nicotinic acid or fibrate treatment; HDL cholesterol level $<40 \mathrm{mg} / \mathrm{dl}(1.0 \mathrm{mmol} / \mathrm{l})$ in men and $<50 \mathrm{mg} / \mathrm{dl}(1.3 \mathrm{mmol} / \mathrm{l})$ in women or nicotinic acid or fibrate treatment; fasting glycaemia $\geq 100 \mathrm{mg} / \mathrm{dl}$ $(5.6 \mathrm{mmol} / \mathrm{l})$ or medication for diabetes; systolic blood pressure $\geq 130 \mathrm{~mm} \mathrm{Hg}$ or diastolic blood pressure $\geq 85 \mathrm{~mm} \mathrm{Hg}$ or antihypertensive medication use. In additional analyses, the International Diabetes Federation (IDF) definition and the original 2001 NCEP ATP III criteria were used for comparisons. ${ }^{10} 12$

\section{Follow-up and CHD events ascertainment}

At each follow-up visit, subjects were asked to report any new severe medical event or hospitalisation since the last contact. For all subjects reporting a possible CHD event, all available clinical information was collected including emergency medical service and hospitalisation reports, interview with the patient's physician or the family. CHD events were validated by an independent expert committee. CHD was defined as hospitalised angina pectoris, hospitalised myocardial infarction, CHD death (I210I219, I251-I259 and I461 ICD-10 codes), or revascularisation (percutaneous intervention or coronary artery bypass-grafting). Incident CHD status was known for $97 \%$ of the participants.

\section{Statistical analysis}

The baseline characteristics were compared according to the presence of the MetS using $\chi^{2}$ tests (or Fisher's exact test when appropriate) and Student tests for categorical and continuous variables respectively. Cox proportional hazard regression was used to estimate the HRs of the MetS for CHD over 6 years. HRs were adjusted for age, gender, study center, educational level (<9, 9-11, $\geq 12$ years), living alone, incapacity in IADL, smoking status (never, former, current), LDL cholesterol level and statin treatment on an a priori basis. Analysis was performed in the whole cohort and by gender. An interaction term between gender and the MetS was included in the model and the Wald test was used to evaluate the statistical signifi- cance of the interaction term. To identify the criteria of the MetS the most predictive of CHD events, all components of the MetS were considered in a single model together with the baseline confounders mentioned above. To assess the respective association of the MetS and its individual components with CHD, all the components of the MetS and the MetS were then included in the same model together with the baseline confounders. In additional analyses, the analyses were repeated using either the IDF or the 2001 NCEP criteria. The added value of the MetS for CHD risk prediction was quantified by calculating net reclassification improvement (NRI) between the risk factors base model that included age, gender, study center, educational level $(<9,9-11, \geq 12$ years), living alone, incapacity in IADL, smoking status (never, former, current), LDL cholesterol level and statin treatment, and the 'novel' model additionally including the MetS. ${ }^{15}$ For comparison, we also calculated the NRI between the risk factors base model and a model additionally including the five components of the MetS in their continuous form. We used the 10-year Framingham CHD risk categories $(<10 \%, 10 \%-20 \%$ and over $20 \%)$ interpolated to 6 years of follow-up $(<6 \%, 6 \%-12 \%$ and over $12 \%)$ to compute the NRI. We also calculated the Harell-C index, an extension of the area under the receiving operating curves suited for censored data, to separately estimate whether the addition of the MetS and of its individual components increased the discrimination ability of the risk factors base model. ${ }^{16}$ The $95 \%$ CIs of the Harell-C indexes of each model together with differences between the Harell-C indexes, were internally validated by bootstrapping with 1000 replications. The proportional hazards assumption of the Cox proportional hazard model was checked using Schoenfeld's global test. All statistical tests were twosided using a type I error of 0.05 . Analyses were computed using STATA $^{\circledR}$ (release 11).

\section{RESULTS}

\section{Baseline characteristics}

Of the 9294 study participants, 1114 were excluded since they had a personal history of CHD at baseline $(n=1105)$ or had their baseline CHD status unknown $(n=9)$. There were 568 additional subjects with missing information on the MetS status at baseline. They were 3 years older on average, more often women, alone, hypertensive, diabetics, less educated, and had higher mean triglycerides and lower mean HDL cholesterol than the 7612 subjects with available MetS at baseline (Flow chart on supplemental figure 1).

The median age of the 7612 participants was 73.2 years (inter quartile range: 69.5-77.4) and 63\% were women. The MetS as defined by the 2005-revised NCEP ATP III criteria was present in $29.2 \%$ of the participants, $29.4 \%$ in women and $28.9 \%$ in men. The baseline characteristics of the participants according to the presence of the MetS are reported in table 1 separately in women and men.

\section{Association between the MetS and new CHD events}

During a median follow-up of 5.2 years, 110 subjects with the MetS (10 with revascularisation, 39 with angina, 33 with myocardial infarction and 28 with fatal CHD) and 165 without the MetS (two with revascularisation, 67 with angina, 66 with myocardial infarction, and 30 with fatal $\mathrm{CHD}$ ) experienced a first CHD event. This yielded a mean annual CHD incidence rate of 10.63 (95\% CI 8.67 to 12.81 ) per 1000 person-years in subjects with the MetS compared to 6.40 (95\% CI 5.49 to 7.45 ) per 1000 person-years in subjects without the MetS $(p<0.001)$. 
Table 1 Baseline characteristics by gender according to the presence of the MetS*

\begin{tabular}{|c|c|c|c|c|c|c|}
\hline & \multicolumn{3}{|l|}{ Women } & \multicolumn{3}{|l|}{ Men } \\
\hline & $\begin{array}{l}\text { No MetS } \\
n=3,367\end{array}$ & $\begin{array}{l}\text { MetS } \\
n=1,400\end{array}$ & $\mathbf{p} \dagger$ & $\begin{array}{l}\text { No MetS } \\
n=2,022\end{array}$ & $\begin{array}{l}\text { MetS } \\
n=823\end{array}$ & $\mathbf{p} \dagger$ \\
\hline Age, years & $73.7(5.4)$ & $74.3(5.2)$ & 0.0003 & $73.8(5.5)$ & $73.6(5.2)$ & 0.457 \\
\hline$<9$ years & $1105(32.9)$ & $561(40.1)$ & $<0.001$ & $532(26.3)$ & $281(34.2)$ & $<0.001$ \\
\hline $9-11$ years & $1081(32.1)$ & $477(34.1)$ & & $529(26.2)$ & $220(26.8)$ & \\
\hline$\geq 12$ years & $1178(35.0)$ & $361(25.8)$ & & $960(47.5)$ & $321(39.1)$ & \\
\hline \multicolumn{7}{|l|}{ Smoking status } \\
\hline Never smoking & $2720(80.8)$ & 1151 (82.3) & 0.484 & $676(33.4)$ & $223(27.2)$ & 0.002 \\
\hline Former smoking & $503(14.9)$ & $195(13.9)$ & & $1162(57.5)$ & $530(64.6)$ & \\
\hline Current smoking & $143(4.3)$ & $53(3.8)$ & & $184(9.1)$ & $68(8.3)$ & \\
\hline Number of pack-years $\ddagger$ & $16.8(18.8)$ & $18.5(22.2)$ & 0.263 & $23.4(21.4)$ & $26.2(22.7)$ & 0.011 \\
\hline $\mathrm{BMI}, \mathrm{kg} / \mathrm{m}^{2}$ & $24.3(3.8)$ & $27.7(4.7)$ & $<0.0001$ & $25.3(3.0)$ & $28.0(3.7)$ & $<0.0001$ \\
\hline Anti-hypertensive drug(s) & 1319 (39.2) & $895(63.9)$ & $<0.001$ & 775 (38.3) & $483(58.7)$ & $<0.001$ \\
\hline Aspirin treatment & $438(13.0)$ & $198(14.2)$ & 0.285 & $325(16.1)$ & $151(18.5)$ & 0.129 \\
\hline \multicolumn{7}{|l|}{ MetS criteria } \\
\hline Abdominal obesity criteria & $669(21.2)$ & $851(65.7)$ & $<0.001$ & $273(14.4)$ & $437(57.4)$ & $<0.001$ \\
\hline Triglycerides criteria & $241(7.2)$ & $1128(80.9)$ & $<0.001$ & $205(10.1)$ & $636(77.6)$ & $<0.001$ \\
\hline HDL chol. criteria & $186(5.5)$ & $1052(75.5)$ & $<0.001$ & $47(2.3)$ & $501(61.1)$ & $<0.001$ \\
\hline Glucose criteria & $153(4.6)$ & $515(38.2)$ & $<0.001$ & $243(12.0)$ & $449(56.0)$ & $<0.001$ \\
\hline Blood pressure criteria & $2633(78.2)$ & 1356 (96.9) & $<0.001$ & $1749(86.5)$ & 808 (98.2) & $<0.001$ \\
\hline
\end{tabular}

The Three-City Study.

The age and study center adjusted cumulative hazard of first CHD events were plotted by baseline MetS status and by gender and were derived from a Cox proportional hazard regression model. Results are numbers (\%) or means (SDs) for qualitative or quantitative data respectively.

*MetS as defined by the revised 2005 National Cholesterol Education Program Adult Treatment Panel III criteria.

tp Value are based on $\chi^{2}$ (or Fisher exact) or Student tests for qualitative or quantitative data respectively. Compared groups are Mets versus no Mets.

$\ddagger$ Number of pack-years in current or former smokers.

BMI, Body Mass Index; CHD, coronary heart disease; chol, cholesterol; HDL, High-Density Lipoprotein; IADL, Instrumental Activity of Daily Living; LDL, Low-Density Lipoprotein; MetS,

Metabolic syndrome.

CHD incidence rates were significantly higher in subjects with compared to subjects without the MetS in women only (Supplemental figure 2).

As shown in table 2, in multivariate adjusted analysis, subjects with the MetS had a significant increased risk of total CHD (HR: 1.78; 95\% CI 1.39 to 2.28), fatal CHD (HR: 2.40; 95\% CI 1.41 to 4.09 ) and non-fatal CHD events (HR: 1.64; 95\% CI 1.24 to 2.17$)$. There was a significant quantitative interaction with gender: the multivariable HRs for total CHD were 2.56 (95\% CI 1.75 to 3.75 ) in women compared to 1.39 (95\% CI 0.99 to 1.94) in men ( $\mathrm{p}$ for interaction: 0.012). After excluding subjects with type 2 diabetes at baseline $(n=665 ; 62 \mathrm{CHD}$ events), the association with the MetS remained highly significant for fatal CHD events in the overall cohort and in women.

\section{Respective association of the MetS and its components with new CHD events}

As shown in figure 1, when all the MetS components were in the same Cox model together with baseline confounders, elevated fasting glycaemia (HR: 2.22; 95\% CI 1.69 to 2.92) and lower HDL cholesterol (HR: 1.52; 95\% IC: 1.06-2.18) were the criteria significantly associated with total CHD events in the overall cohort. In women, they were elevated fasting glycaemia $(\mathrm{HR}=2.47 ; 95 \% \mathrm{CI} 1.56$ to 3.87$)$ and elevated abdominal adiposity ( $\mathrm{HR}=1.57 ; 95 \%$ IC: $1.03-2.41)$. In men they were elevated fasting glycaemia ( $\mathrm{HR}=2.04 ; 95 \% \mathrm{CI} 1.45$ to 2.87$)$, lower HDL cholesterol ( $\mathrm{HR}=1.72 ; 95 \% \mathrm{CI} 1.06$ to 2.79 ) and elevated abdominal adiposity ( $\mathrm{HR}=0.59 ; 95 \%$ CI 0.39 to 0.90$)$.
After further adjustment for the MetS, the significant components and the magnitude of their association with CHD remained the same whereas the MetS was no longer associated with CHD (HR: $0.89 ; 95 \%$ CI 0.53 to 1.49 ) in the overall cohort. The same findings were observed in analyses stratified by gender (not shown).

\section{Improvement in discrimination for CHD risk associated with the MetS and its components}

As shown in table 3, adding the MetS to a risk factors base model that comprised age, gender, study center, educational level, living alone, incapacity in IADL, smoking status, LDL cholesterol and statin treatment modestly improved discrimination, that is, the capacity to differentiate those who will suffer a CHD event from those who will not, since $3.12 \%$ of the individuals were reclassified in adequate risk categories $(p=0.06)$. By contrast, adding the components of the MetS (in their continuous form) significantly improved discrimination of the risk factors base model, since $9.35 \%$ of the individuals were reclassified in adequate risk categories $(p<0.001)$. Similarly, adding the MetS to the risk factors base model marginally improved the value of the Harell-C-index (from 0.706 to 0.718 ) contrary to the addition of the individual components of the MetS (from 0.706 to 0.761 ).

\section{Additional MetS definitions}

The frequency of the MetS remained similar when the IDF definition was used $(28.6 \%)$ but was of $14.2 \%$ when the 2001 
Table 2 Incidence rates of CHD and HRs of the MetS* for CHD

\begin{tabular}{|c|c|c|c|}
\hline & Total & Women & Men \\
\hline Total cohort & $n=7612$ & $n=4767$ & $n=2845$ \\
\hline Total CHD events & 275 & 112 & 163 \\
\hline Incidence rate/1000 PY (95\% Cl) & $7.6(6.8$ to 8.6$)$ & $4.8(4.0$ to 5.8$)$ & $12.5(10.7$ to 14.6$)$ \\
\hline $\mathrm{HR}+(95 \% \mathrm{Cl})$ & 1.78 (1.39 to 2.28$)$ & $2.56(1.75$ to 3.75$)$ & 1.39 (0.99 to 1.94$)$ \\
\hline Fatal CHD events & 58 & 25 & 33 \\
\hline Incidence rate/1000 PY (95\% Cl) & $1.6(1.2$ to 2.1$)$ & $1.1(0.7$ to 1.6$)$ & $2.5(1.8$ to 3.6$)$ \\
\hline $\mathrm{HR} \dagger(95 \% \mathrm{Cl})$ & 2.40 (1.41 to 4.09 ) & 3.89 (1.65 to 9.19$)$ & $1.69(0.82$ to 3.47$)$ \\
\hline Non-fatal CHD events & 217 & 87 & 130 \\
\hline Incidence rate/1000 PY (95\% Cl) & $6.0(5.3$ to 6.9$)$ & $3.8(3.0$ to 4.6$)$ & $10.0(8.4$ to 11.9$)$ \\
\hline $\mathrm{HR} \dagger(95 \% \mathrm{Cl})$ & 1.64 (1.24 to 2.17$)$ & 2.30 (1.49 to 3.53$)$ & $1.31(0.90$ to 1.91$)$ \\
\hline Non-diabetic & $\mathrm{n}=6869$ & $n=4393$ & $\mathrm{n}=\mathbf{2 4 7 6}$ \\
\hline Total CHD events & 209 & 84 & 125 \\
\hline Incidence rate/1000 PY (95\% Cl) & $6.3(5.5$ to 7.3$)$ & 3.9 (3.2 to 4.8$)$ & $10.9(9.1$ to 13.0$)$ \\
\hline $\mathrm{HR} \dagger(95 \% \mathrm{Cl})$ & $1.15(0.84$ to 1.57$)$ & 1.52 (0.96 to 2.42$)$ & 0.93 (0.60 to 1.44$)$ \\
\hline Fatal CHD events & 45 & 19 & 26 \\
\hline Incidence rate/1000 PY (95\% CI) & $1.4(1.0$ to 1.8$)$ & $0.9(0.6$ to 1.4$)$ & $2.3(1.5$ to 3.3$)$ \\
\hline $\mathrm{HR} \dagger(95 \% \mathrm{Cl})$ & $2.23(1.20$ to 4.14$)$ & 3.09 (1.19 to 8.02$)$ & 1.77 (0.76 to 4.12$)$ \\
\hline Non-fatal CHD events & 164 & 65 & 99 \\
\hline Incidence rate/1000 PY (95\% Cl) & 5.0 (4.3 to 5.8$)$ & $3.0(2.4$ to 3.9$)$ & 8.6 (7.1 to 10.5$)$ \\
\hline $\mathrm{HR} \dagger(95 \% \mathrm{Cl})$ & $0.94(0.65$ to 1.36$)$ & $1.21(0.70$ to 2.10$)$ & $0.78(0.47$ to 1.30$)$ \\
\hline
\end{tabular}

The Three-City Study.

*As defined by the revised 2005 National Cholesterol Education Program Adult Treatment Panel III criteria.

†HRs from Cox proportional hazard models adjusted for age, study center, educational level, living alone, incapacity in instrumental activities of daily living, smoking status, LDL cholesterol, statin treatment, and gender when appropriate.

CHD, coronary heart disease; MetS, Metabolic syndrome; PY, Person-Years.

NCEP ATP III criteria were employed. By contrast associations with CHD were of comparable magnitude whatever the MetS definitions used (Supplemental table 1).

\section{DISCUSSION}

In this large prospective cohort of community-dwelling subjects aged 65 and over the MetS as defined by the revised 2005 NCEP ATP III was associated with an $80 \%$ increased risk of total CHD events independently of baseline confounders, with a significantly stronger association in women compared to men. However, the MetS failed to improve significantly discrimination for CHD risk, contrary to its individual components.
With the Cardiovascular Health Study, this is the sole community based cohort of elderly subjects covering a wide range of age over 65 years. ${ }^{6}$ Remaining studies covered a narrowed age range, 70-79 years in the Health Ageing and Body Composition Study, 65-74 years in a Finn study and 60-79 years in the British Women's Heart and Health Study. ${ }^{7-9}$ Most previous studies used the MetS as defined by the 2001 NCEP ATP III criteria in which treatments for hypertension, dyslipidemia and hyperglycemia are not considered. Elderly subjects represent a highly treated population and exclusion of these treatments may affect the frequency of the MetS and the strength of its association with CHD events in this population. As shown here, the frequency of the MetS was twice less
Figure 1 Mutually adjusted HRs of the individual components of the MetS* for CHD. The Three City Study.

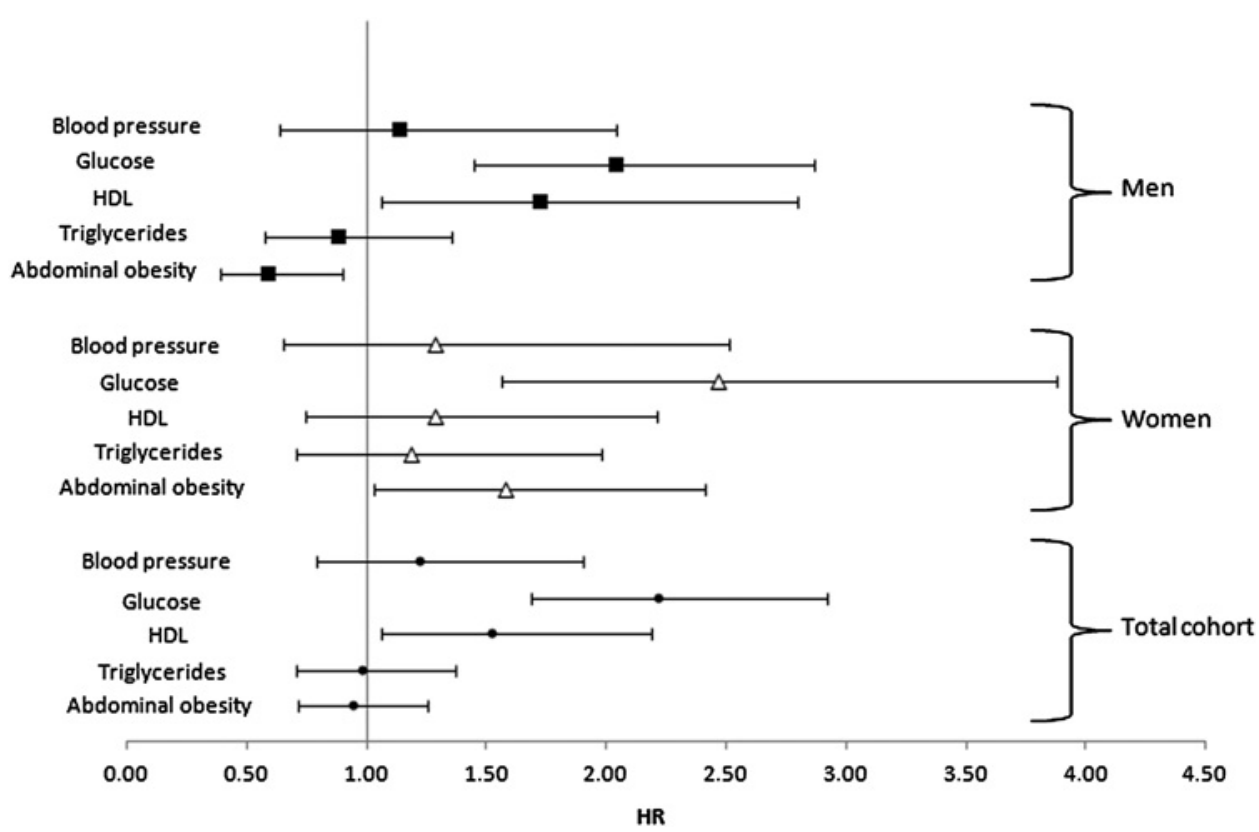


Table 3 Harell-C index and net reclassification improvement associated with the MetS and its individual components

\begin{tabular}{|c|c|c|c|c|c|}
\hline Model & Harell-C index & $\mathbf{9 5 \%} \mathrm{Cl}$ & p Value* & NRI \% & p Value \\
\hline Risk factors base model & 0.706 & 0.705 to 0.707 & - & - & - \\
\hline+ MetS† & 0.718 & 0.717 to 0.719 & $<0.001$ & 3.12 & 0.06 \\
\hline + Individual components of the MetS & 0.761 & 0.760 to 0.762 & $<0.001$ & 9.35 & $<0.001$ \\
\hline
\end{tabular}

The Three City Study.

The risk factors base model includes age, study center, educational level, living alone, incapacity in instrumental activities of daily living, smoking status, LDL cholesterol, statin treatment, and gender as covariates.

*The $95 \% \mathrm{Cl}$ of the Harell-C indexes and difference between the Harell-C indexes were obtained after 1000 bootstrapping with replications.

†Revised 2005 National Cholesterol Education Program Adult Treatment Panel III criteria.

MetS, metabolic syndrome; NRI, net reclassification improvement.

frequent using the 2001 NCEP ATP III criteria compared to the 2005 ATP criteria or the IDF definition that include treatments. By contrast, there was little variation in CHD risk between the 2001 NCEP ATP III definition, the 2005 revised NCEP ATP III definition or the IDF definition in the current study.

The current study suggests that the association of the MetS with CHD was stronger for fatal than non-fatal CHD events. The inclusion of revascularisation in the definition of non-fatal events may have reduced their association with the MetS. However, excluding revascularisation from the definition of nonfatal events did not change this pattern of association (not shown). Moreover, this may reflect a particular association with sudden arrhythmic death as previously shown in middleaged men. ${ }^{17}$ The possibility that subjects with the MetS have more severe coronary artery lesions (which may increase their risk of CHD death) is not currently supported by angiographic findings. ${ }^{18} 19$

We found a stronger association between the MetS and CHD in women compared to men with a highly significant gender interaction. This has been previously observed in the middleaged population and has been confirmed in two recent metaanalyses. $^{3} 4$ More conflicting results on this issue has been reported in the elderly. ${ }^{6-9}$ The putative reasons for this gender interaction remain unclear. The stronger association between type 2 diabetes and CHD in women compared to men has been advocated. ${ }^{20} 21$ In the current study however, this gender interaction persisted after the exclusion of subjects with type 2 diabetes at baseline. Second, abdominal adiposity may contribute to this gender interaction as it was predictive of $\mathrm{CHD}$ in women and inversely associated with CHD in men. While this intriguing inverse association between abdominal adiposity and CHD risk in men may be due to chance, a comparable finding was recently reported for Alzheimer's disease risk. ${ }^{22}$ Interestingly, in the current study, the gender interaction was no longer observed when the study population was stratified by abdominal adiposity level, the p values for interaction being 0.31 and 0.77 respectively in the obese and the non-obese subjects (not shown). Finally, there may be biological interactions between the individual components of the MetS in women and not or of less importance in men. In the current study, the likelihood ratio of a model predicting $\mathrm{CHD}$ and including individual MetS components plus two by two interaction terms was significantly better than the model without interactions in women but not in men (data not shown).

The respective contribution of the MetS and of its individual components for $\mathrm{CHD}$ risk remains a matter of debate. ${ }^{23-25}$ In the current study, several findings argue against the potential clinical usefulness of the MetS to predict the risk of CHD. First, the association between the MetS and CHD events was of lower magnitude than that between elevated fasting glycaemia-the most significant component- and CHD. Second, the MetS was no longer associated with CHD after adjustment for its compo- nents. Similar observations have been recently reported in a limited sample of 1221 Swedish men over 70 years for total and cardiovascular mortality, but CHD morbidity was not investigated in that study. ${ }^{26}$ By contrast, in the Cardiovascular Health Study, the MetS as defined by the 2001 NCEP-ATP III criteria remained predictive of $\mathrm{CHD}$ and stroke even after adjustment for its components, although this adjustment attenuated substantially its HR. ${ }^{27}$ Third, our study shows that the MetS failed to improve in a clinically relevant manner discrimination for CHD risk beyond baseline confounders not including the MetS components. By contrast, discrimination was substantially improved by the addition of the components of the MetS. This latter finding re-emphasises that the classical risk factors remain the cornerstone for $\mathrm{CHD}$ risk stratification purposes.

The current study has some limitations. Analysis was based on a single measurement of the MetS. The thresholds currently used for the definition of the MetS may not be suitable for an older population. Residual confounding cannot be excluded and in particular, socioeconomic position from across the life-course has been suggested to be an important confounder, at least in British elderly women. ${ }^{9}$ The current study includes wellfunctioning, highly educated subjects and mostly Caucasians, needing caution before extrapolating these results to the frailest and other ethnic groups.

\section{CONCLUSION}

In summary, in this large prospective study of non-institutionalised elderly men and women, the MetS was an independent risk marker of $\mathrm{CHD}$ events especially in women. However, while the individual components of the MetS improved significantly discrimination for $\mathrm{CHD}$ risk beyond baseline confounders, the MetS did not. Therefore, a systematic assessment of the MetS may not be suitable for CHD risk stratification purposes in the elderly.

Acknowledgements Marie-Cécile Périer for statistical support.

Contributors Conception and design: C. Tzourio, P. Ducimetière Analysis and interpretation of data: A. Rachas, J.P. Empana Drafting the article: A. Rachas, J.P. Empana Critically revising the article for important intellectual content: A. Rachas, C. Raffaitin, P. Barberger-Gateau, C. Helmer, P. Ducimetière, J.P. Empana Final approval of the manuscript: all authors.

Funding The Three-City Study was conducted under a partnership agreement between the Institut National de la Santé et de la Recherche Médicale (INSERM), the Victor Segalen-Bordeaux II University, and Sanofi-Aventis. The Fondation pour la Recherche Médicale funded the preparation and initiation of the study. The 3C Study was also supported by the Caisse Nationale Maladie des Travailleurs Salariés, Direction Générale de la Santé, MGEN, Institut de la Longévité, Conseils Régionaux of Aquitaine and Bourgogne, Fondation de France, and Ministry of Research-INSERM Programme "Cohortes et collections de données biologiques." Researchers were independent of funding organisations.

Competing interests None.

Patient consent As mentioned in the manuscript, each participant had signed a french local informed consent. 
Ethics approval The ethics approval was provided by Ethical Committee of the University Hospital of Kremlin-Bicêtre.

Provenance and peer review Not commissioned; externally peer reviewed.

\section{REFERENCES}

1. Hu G, Qiao Q, Tuomilehto J, et al. Prevalence of the metabolic syndrome and its relation to all-cause and cardiovascular mortality in non diabetic European men and women. Arch Intern Med 2004;164:1066-76.

2. Ford ES, Schulze MB, Pischon T, et al. Metabolic syndrome and risk of incident diabetes: findings from the European prospective Investigation into Cancer and Nutrition-Potsdam study. Cardiovasc Diabetol 2008;7:35.

3. Gami AS, Witt BJ, Howard DE, et al. Metabolic syndrome and risk of incident cardiovascular events and death: a systematic review and meta-analysis of longitudinal studies. J Am Coll Cardiol 2007;49:403-14.

4. Mottillo S, Filion KB, Genest J, et al. The metabolic syndrome and cardiovascular risk. A systematic review and meta-analysis. J Am Coll Cardiol 2010;56:1113-32.

5. Empana JP, Zureik M, Gariepy J, et al. The metabolic syndrome and the carotid artery structure in non institutionalized elderly subjects: the three-city study. Stroke 2007;38:893-9

6. Butler J, Rodondi N, Zhu Y, et al. Metabolic syndrome and the risk of cardiovascular disease in older adults. J Am Coll Cardiol 2006:47:1595-602.

7. McNeill AM, Katz R, Girman CJ, et al. Metabolic syndrome and cardiovascular disease in older people: the cardiovascular health study. J Am Geriatr Soc 2006:54:1317-24.

8. Lempiäinen P, Mykkänen L, Pyörälä K, et al. Insulin resistance syndrome predicts coronary heart disease events in elderly non diabetic men. Circulation 1999;100:123-8.

9. Lawlor DA, Smith GD, Ebrahim S. Does the new International Diabetes Federation definition of the metabolic syndrome predict $\mathrm{CHD}$ any more strongly than older definitions? Findings from the British Women's Heart and Health Study. Diabetologia 2006;49:41-8.

10. Expert Panel on Detection, Evaluation, and Treatment of High Blood Cholesterol in Adults. Executive summary of the Third report of the National cholesterol Education Program (NCEP) expert Panel on Detection, Evaluation, and treatment of High blood cholesterol in adults (Adult treatment Panel III). JAMA 2001;285:2486-97.

11. Grundy SM, Cleeman JI, Daniels SR, et al. Diagnosis and management of the metabolic syndrome: an American heart Association/National heart, Lung, and blood Institute Scientific statement. Circulation 2005;112:2735-52.

12. Alberti KG, Zimmet P, Shaw J, et al. The metabolic syndrome: a new worldwide definition. Lancet 2005:366:1059-62.

13. Alberti KG, Eckel RH, Grundy SM, et al; International Diabetes Federation Task Force on Epidemiology and Prevention; Hational Heart, Lung, and Blood Institute; American Heart Association; World Heart Federation; International Atherosclerosis Society; International Association for the Study of Obesity. Harmonizing the metabolic syndrome: a joint interim statement of the International diabetes Federation Task
Force on Epidemiology and Prevention; National heart, Lung, and blood Institute; American heart association; World heart Federation; International Atherosclerosis Society; and International association for the study of obesity. Circulation 2009:120:1640-5.

14. The 3C Study Group. Vascular factors and risk of dementia: design of the ThreeCity Study and baseline characteristics of the study population. Neuroepidemiology 2003;22:316-25.

15. Pencina MJ, D'Agostino RB Sr, D'Agostino RB Jr, et al. Evaluating the added predictive ability of a new marker: from area under the ROC curve to reclassification and beyond. Stat Med 2008;27:157-72

16. Pencina MJ, D'Agostino RB. Overall $\mathrm{C}$ as a measure of discrimination in survival analysis: model specific population value and confidence interval estimation. Stat Med 2004;23:2109-23

17. Empana JP, Duciemetiere P, Balkau B, et al. Contribution of the metabolic syndrome to sudden death risk in asymptomatic men: the Paris Prospective Study I. Eur Heart $J$ 2007;28:1149-54.

18. Hsia J, Bittner V, Tripputi M, et al. Metabolic syndrome and coronary angiographic disease progression: the Women's Angiographic Vitamin \& Estrogen trial. Am Heart J 2003; 146:439-45.

19. Hoffmann R, Stellbrink E, Schröder J, et al. Impact metabolic syndrome angiographic clinical events after coronary intervention using bare-metal or sirolimuseluting stents. Am J Cardiol 2007:100:1347-52.

20. Lee WL, Cheung AM, Cape D, et al. Impact of diabetes on coronary artery disease in women and men: a metaanalysis of prospective studies. Diabetes Care 2000;23:962-8.

21. Yusuf S, Hawken S, Ounpuu $S$, et al. Effect of potentially modifiable risk factors associated with myocardial infarction in 52 countries (the INTERHEART study): case control study. Lancet 2004:364:937-52

22. Raffaitin C, Gin H, Empana JP, et al. Metabolic syndrome and risk for incident Alzheimer's disease or vascular dementia: the Three-City Study. Diabetes Care 2009;32:169-74.

23. Kahn R, Buse J, Ferrannini E, et al; American Diabetes Association; European Association for the Study of Diabetes. The metabolic syndrome: time for a critical appraisal: joint statement from the American diabetes association and the European association for the study of diabetes. Diabetes Care 2005:28:2289-304

24. McNeill AM, Rosamond WD, Girman CJ, et al. The metabolic syndrome and 11year risk of incident cardiovascular disease in the atherosclerosis risk in communities study. Diabetes Care 2005:28:385-90.

25. Grundy SM. Metab syndrome a multiplex cardiovascular risk factor. J Clin Endocrinol Metab 2007:92:399-404.

26. Sundström J, Risérus U, Byberg L, et al. Clinical value of the metabolic syndrome for long term prediction of total and cardiovascular mortality: prospective, population based cohort study. BMJ 2006;332:878-82.

27. Scuteri A, Najjar SS, Morrell CH, et al; Cardiovascular Health Study. The metabolic syndrome in older individuals: prevalence and prediction of cardiovascular events: the Cardiovascular Health Study. Diabetes Care 2005:28:882-7. 